Chapter 12

\title{
Potentials of Phytotherapeutic Treatment of Erectile Dysfunction
}

\author{
Guillaume Aboua, Claudine Manirafasha, \\ Boitumelo R. Mosito, Michelle van der Linde and \\ Stefan S. du Plessis
}

Additional information is available at the end of the chapter

http://dx.doi.org/10.5772/57174

\section{Introduction}

Erectile dysfunction (ED) or (male) impotence is a sexual dysfunction characterized by the inability to develop or maintain an erection of the penis [1]. There are various underlying causes, such as a compromised cardiovascular system and diseases such as diabetes and chronic kidney disease (CKD), many of which are medically treatable. The causes of erectile dysfunction may be physiological or psychological [2]. Sexual function includes libido, penile erection, ejaculation, and orgasm. While each of these parameters may be of concern to an individual patient, the vast majority of men complain of ED. Testosterone deficiency frequently is associated with decreased libido and ED. ED is a clinical problem that is underdiagnosed, under-evaluated, and under-treated. The prevalence of ED increases with age, and it is associated with multiple medical conditions including diabetes, hypertension, and heart disease that also increase with age. ED is a highly prevalent and often underreported condition. The prevalence of ED varies in different countries and approximately 100 million men worldwide are estimated to be affected with ED. More than half of US men between the ages of 40 and 70 years are estimated to have ED. The worldwide ED prevalence in men with diabetes ranges from $27 \%$ to $75 \%$ and it is estimated that the prevalence of ED will double in the next 25 years [3]. There is a strong link between ED and atherosclerotic disease due to the fact that they share similar risk factors. In a study where patients referred for myocardial perfusion single-photon emission computed tomography were screened for ED with a questionnaire, it was found out that $54.8 \%$ of the patients had ED. Patients with ED showed more severe coronary heart disease. In diabetic patients, ED has been shown to predict silent coronary artery disease, and in asymptomatic men without cardiovascular risk factors or 
known vascular disease [4]. Nevertheless, the hypothesis that ED, as a manifestation of autonomic neuropathy, may be linked with the lack of symptoms in a proportion of diabetic patients with silent CAD cannot be excluded [4].

\section{Causes of erectile dysfunction}

ED arises as a result of a collision of many factors: physical, psychological, physiological and biochemical abnormalities. The exact cause of ED is usually difficult to establish because it normally results from an underlying condition such as diabetes and/or heart disease. ED can also be caused by psychological conditions such as stress, depression and anxiety [5]. The physiological mechanism of erection is a complex neurovascular phenomenon that depends on neural, vascular, hormonal, and psychological factors. Integrated function of these factors is essential for production of a normal erectile response [3]. Recent advances in the understanding of functional anatomy and of neurovascular interactions have improved our understanding of the pathophysiological mechanism of ED [3].

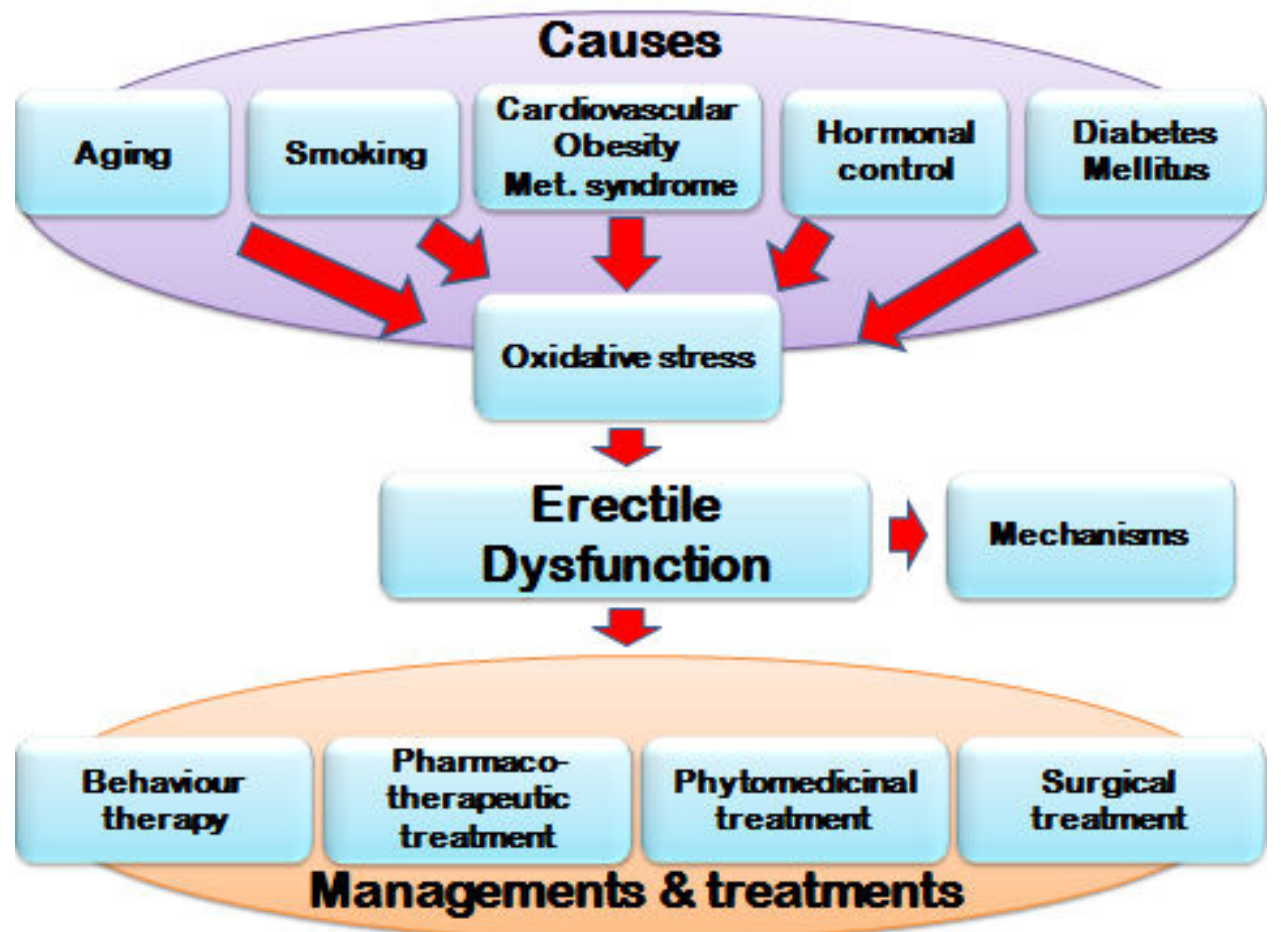

Figure 1. Possible causes, managements and treatment strategies of Erectile Dysfunction 


\subsection{Aging}

Aging has been considered to be one of the major reasons for decreased sexual functions, which are also affected by a change in lifestyle, increased day-to-day stress, depression, diabetes and/ or other metabolic and endocrine disorders. Various medications such as antidepressants, tranquilizers, hypnotics, antiandrogens and antihypertensive agents can also lead to the downfall of the sexual functions [6,7]. There is a close relationship between aging and ED [8]. Research shows that chances of developing ED increase with age and are due to several agerelated factors such as a reduction in nonadrenergic noncholinergic nerve endings in the penis and decreased endothelial nitric oxide (eNOS) activity. The decreased activity of eNOS and bioavailability of NO impairs corpus cavernosum relaxation which can be exacerbated by an increased release of vasoconstrictors. These confounding events are responsible for the increase in the contractile tone in the penile vasculature [9]. Testosterone is secreted in a circadian manner in younger men, but diurnal fluctuation is reduced and may disappear in aging men [10]. Whatever the initiating factor of $\mathrm{ED}$, the ultimate common pathological process is damage to smooth-muscle cells and an increase in the accumulation of fibrosis, which decrease the vasodilator response. This increased accumulation of collagen with aging has been observed in both human and rat corporal smooth muscle [11]. The increase in collagen accumulation leads to a decrease in blood flow as measured by peak systolic velocity, and this decrease of blood flow contributes to ED.

As men age, dysfunction of this complex process occurs with an increased incidence and prevalence. The cause of this age-related erectile dysfunction is not well understood and likely involves multifactorial alterations in the cavernosal endothelial cell lining, smooth muscle cells, and synthesis or activity of NO [12].

\subsection{Oxidative stress}

Oxidative stress (OS) is one of the major contributory factors towards ED. There is a growing interest among researchers regarding the role of oxidative stress in the pathophysiological mechanism of ED. Oxidative stress occurs when there is an imbalance between pro-oxidants and the ability of the antioxidants to scavenge excess reactive oxygen species (ROS) [3]. Penile erectile tissue is formed by 2 dorsal corporal bodies known as the corpora cavernosa. The cavernosal bodies are composed of sinusoidal spaces with a trabecular meshwork. These spaces are lined by endothelium. Neural transmitters, such as acetylcholine, are released from cavernosal nerve endings and stimulate the neuronal NOS (nNOS) enzyme, which leads to the release of NO from the endothelium. Erectile function is mediated by both nNOS and endothelial NOS (eNOS) [13]. NO is the principal mediator of penile erection [13]. Erectile function is dependent on relaxation of the cavernous smooth muscle, and its mechanism of action is dependent on penile smooth muscle relaxation, mediated by NO. Decreased production or absence of NO may play a major role in ED. Production decreases when the availability of substrate for NOS is reduced. NO is a highly reactive free radical that undergoes nonenzymatic reaction with the heme moiety of oxyhemoglobin or that reacts with free radicals, such as superoxide anion, to form peroxynitrite [14]. The relationship between OS in the penis and age related ED has only been recently investigated and it was shown that as one ages, free radicals 
are produced at a higher rate and their numbers increase in various vascular beds. These mechanisms ultimately produce an ineffective relaxation in cavernosal tissue, which leads to ED. NO interacts with superoxide to form peroxynitrite, which has been reported to play a central role in atherogenesis [14]. Peroxynitrite reacts with the tyrosyl residue of proteins, which inactivates superoxide dismutase (SOD) and Leads to decrease the removal of superoxide [15]. Previous studies have shown that penises from old rats display an increase in nitrotyrosine immunostaining which is a marker for peroxynitrite formation. Due to aging, there is not enough SOD produced to balance superoxide anions produced in aged rat penises, which is why their endothelium and corpus cavernosal smooth muscle display high amounts of superoxide anions as opposed to those of younger animals. Therefore, as extracellular SOD is transferred to aged rats, erectile dysfunction is restored because the superoxide anion formation is reduced [5]. Oxidative and nitrosative stress is associated with infertility, and directly involved in reproductive disorders as diverse as oocyte implantation, endometriosis, and pre-eclampsia in women, and ED, sperm damage and motility in men [16]. NO is reported to decrease the adhesion of platelets and leukocytes to the vascular endothelial cells. A reduced NO concentration aggravates the adhesion of these cells to the endothelium and releases substances (thromboxane A2 and leukotriens) that cause vasoconstriction. These substances further aggravate ED [5].

Hypercholesterolemia is associated with increased ultrastructural predisposition to atherosclerosis and decreased cavernosal smooth-muscle relaxation [17]. Increased cavernosal superoxide levels in hypercholesterolemia may decrease the availability of NO, which may lead to the development of ED. Decreased NO bioavailability in obesity-prone animals has been shown to be due, in part, to increased OS [18]. Oxidative modification of LDL (oxLDL), the major carrier of plasma cholesterol, plays a crucial role in hypercholesterolemia and atherosclerosis development. LDL can undergo oxidative modification by superoxide and peroxynitrite, and it accumulates in atherosclerotic plaques. OxLDL also increases the production of caveolin-1 and its association with eNOS affecting the balance of NO and superoxide generation by eNOS and uncoupling eNOS activity [18]. In human vascular endothelial cells, oxLDL stimulates OS via induction of NAD(P)H oxidase [19].

\subsection{The effects of cardiovascular disease, obesity, metabolic syndrome on erectile dysfunction}

Obesity is normally associated with generally accepted ED risk factors such as hypertension, hyperlipidaemia, and diabetes but has recently been categorised as an independent cause of ED. An age adjusted BMI has been found to be significantly high in men who have reported severe ED as well as those that are sexually inactive, and this indicates that obesity is a strong predictor of ED. In several analyses from previous studies, obesity remained a major independent predictor of increasingly severe ED [20]. Furthermore, Gazzaruso et al. (2004) suggested that ED could be considered to be the most efficient predictor of silent coronary heart disease (CHD) in a diabetic population, independently of glycometabolic control and ED severity [4]. The interest that is currently being addressed to inflammatory markers is not fortuitous, considered the link between obesity, type II diabetes mellitus and atherosclerotic 
cardiovascular disease, three pathological conditions increasingly recognized as having an inflammatory genesis, and increasing the risk of ED [21].

Erectile dysfunction represents an early surrogate marker of forthcoming cardiovascular disease (CVD) [22]. It has been hypothesized that ED becomes evident earlier than CVD because the smaller penile arteries reach critical narrowing, with insufficient blood flow, earlier than larger vessels [23].

The recognition of ED, focusing attention on risk profile, could be of help in the prevention of CVD. ED can be used to screen for the presence of hypogonadism, metabolic syndrome, hypertension and silent CVD [24].

Abnormalities of the vasodilator system play an important role in the pathophysiology of ED as it is now recognized as a common cause of $\operatorname{ED}[25,26]$. Therefore, the earliest events in the development of atherosclerosis (endothelial dysfunction) are similar to the earliest events in the development of ED [27] have suggested that a diagnosis of ED is a sentinel event that should prompt investigation for CHD in asymptomatic men [27] Interestingly enough, Kaiser et al [28] recently reported that subjects with ED but without evidence of clinical cardiovascular disease and free of traditional cardiovascular risk factors present widespread abnormality of endothelial function as has been seen in patients with cardiovascular risk factors. Thus, many patients with ED seem to have a vascular mechanism similar to that seen in atherosclerosis [29].

\subsection{Smoking}

Several studies were carried out in order to confirm that smoking is an independent risk factor for ED [30]. An example being a study that excluded diabetic patients that was controlled for other factors such as age, trauma history and hypertension concluded that smoking is independently associated with atherosclerosis in the pudendal artery. Tengs and Osgood carried out study in 2001 and reported that $40 \%$ of impotent men were current smokers as opposed $28 \%$ men in the general population [30]. Cross-sectional studies have reported that smoking is an independent risk factor for ED.

\subsection{Diabetes mellitus}

Over the years, diabetes mellitus has been known as one of the major direct causes of ED. Research has proved that the probability of ED occurrence is higher in diabetic men than nondiabetic men of the same age and that this difference increases with age. In previous studies, it has been estimated that $50 \%-75 \%$ of men with diabetes have ED [32]. Most of the vascular complications that are linked to both Type 1 and Type 11 diabetes are a result of hyperglycaemia, but the majority of studies apply to Type 1 diabetes. The impairment of NOS activity and the numerical reduction of nerves containing NOS are the reasons behind diabetes-associated ED. Neurogenic and endothelium controlled relaxation of the smooth muscle as well as the downregulation of mediators downstream from NO such as cGMP and cGMP-dependent protein kinase in the corpus cavernosum are also involved in ED caused by diabetes [33]. 
ED is an important component of the metabolic or insulin resistance syndrome, as demonstrated by inadequate vasodilation and/or paradoxical vasoconstriction in coronary and peripheral arteries in response to stimuli that release NO [34]. Metabolic actions of insulin to promote glucose disposal are augmented by vascular actions of insulin in endothelium to stimulate production of the vasodilator NO [8]. Metabolic insulin resistance is characterized by pathway specific impairment in PI3K-dependent signalling, which may cause imbalance between production of $\mathrm{NO}$ and secretion of ET-1 in the endothelium, leading to decreased blood flow, which exacerbates insulin resistance [17]. Deficiency of endothelial-derived NO is believed to be the primary defect that links insulin resistance and ED. NO deficiency results from decreased synthesis and/or release, in combination with exaggerated consumption in tissues by high levels of reactive oxygen (ROS) and reactive nitrogen (RNS) species, which are produced by cellular disturbances in glucose and lipid metabolism. ED contributes to impaired insulin action, by altering the transcapillary passage of insulin to target tissues. Reduced expansion of the capillary network, with attenuation of microcirculatory blood flow to metabolically active tissues, contributes to the impairment of insulin stimulated glucose and lipid metabolism. This establishes a reverberating negative feedback cycle in which progressive ED and disturbances in glucose and lipid metabolism develop secondarily to the insulin resistance [35]. Studies were done on rats to show that transfer of the adenovirus mediated gene of eNOS to the diabetic rat penis can improve the decreased erectile response by causing an increase in cGMP formation [36]. An additional reason for the decreased eNOS activity in the diabetic rat penis is that there is a reduced L-arginene content. A study was carried out in which diabetic rats were orally administered L-arginine, and results indicated increased endothelium dependent relaxation of cavernosal tissue by improvment of the biosynthesis of NO which ultimately led to an increased erectile response [37].

\subsection{Hormonal control on erectile dysfunction}

There may be a link between insulin resistance, endothelial dysfunction, metabolism syndrome, ED, and diabetes [35]. Hypogonadism has been shown to be an independent determinant of endothelial dysfunction, thus contributing to vascular pathology, including ED [35]. Testosterone (T) and its metabolites, dihydrotestosterone (DHT) and estradiol (E2), have a critical role in the development and maintenance of normal male genitalia, testes, accessory sex organs, skeletal muscle mass, bone growth mass, male hair patterns, libido and erectile function [38]. Testosterone is also thought to influence central nervous system gender identification [39]. DHT as well as testosterone can maintain libido and erectile function, indicating that estrogen is not required for their maintenance in men [40]. Androgen receptors (ARs) are present in the amygdala, lateral septum, and premamillary bodies in male primates [41]. AR linked brain sites in the hypothalamus, pituitary gland and preoptic areas appear to influence male sexual behaviour. For instance, stimulation of forebrain, hippocampus, and hypothalamic nuclei causes penile erection and/or mating behaviour in laboratory animals [42, 43]. Other studies indicate that the hypothalamic paraventricular nuclei could be the main source of a descending spinal erection pathway to the spinal erection generator [44]. 
Several studies have shown that acute administration of $\mathrm{T}$ induces rapid relaxation in vascular tissues of different species including humans $[45,46]$ suggesting a non-genomic effect of this hormone on vasomotion [47]. Different mechanisms have been proposed to explain T-induced vasodilatation, [48] but as to which are the effective mechanisms and which are the mediators involved with the T-induced vasorelaxation remain a matter of debate. Testosterone might induce relaxation in human isolated corpora cavernosa strips by activation of smooth muscle adenosine triphosphatesensitive $\mathrm{K}(+)$ channels. This finding suggests that $\mathrm{T}$, in addition to its known endothelial action, might regulate erectile function locally by its action on the smooth muscle of the human corpus cavernosum [49 It has been established that different thresholds exist for sexual desire and erectile function in humans, the former being quite higher than the latter [50]. In humans, T deficiency determines a sequence of molecular penile events leading to reduced capacity of smooth muscle and endothelial cells to relax in addition to causing increased sensitivity to contractile factors, that is, alpha-adrenergic agonists and deficiency of NO-induced relaxation during sexual stimulus. Recent evidence in humans suggest that $\mathrm{T}$ may directly control the expression and activity of phosphodiesterase type 5 (PDE5) in human corpus cavernosum so that in some selected patients, that is, total- $\mathrm{T}<10 \mathrm{nmol} / \mathrm{L}$ and/or freeT below $200 \mathrm{nmol} / \mathrm{L}$, androgen supplementation may improve therapeutic efficacy to PDE5-i [8]. Reduced production of testosterone may increase the risk of osteoporosis, sexual dysfunction, fatigue, cardiovascular disease and mood disturbances, and may decrease muscle mass [51]. Hypogonadism may be classified as hypergonadotrophic in cases of testicular failure or hypogonadotrophic in cases of hypothalamic/pituitary failure [51]. Finally, penile NO, the major smooth muscle relaxer responsible for penile erections, is in part regulated by testosterone. To date, it is not known if the peripheral androgenic effects observed in animals also are present in man 52].

\section{Mechanisms}

Various mechanisms may disturb the regulatory function of eNOS and endothelial NO bioavailability, resulting in vasculogenic ED. As molecular mechanisms of normal erectile function and the pathways leading to vasculogenic ED associated with eNOS are becoming clearer, it seems that eNOS roles in the vascular pathophysiology of the penis are complicated and not always uniform. For example, eNOS phosphorylation in the penis is ineffectively regulated with aging and diabetes, although by different mechanisms. However, increased oxidative stress in the penis seems to be a common component of vasculogenic ED, and activation of the RhoA/ Rho-kinase contractile pathway is seen in several vasculogenic ED states [53].

\section{Management and treatments of erectile dysfunction}

Erectile dysfunction is a defect of penis reaching and or sustaining erection because of physiological or psychological factors [2]. Different treatments have been proposed including: 
- Psychological/behavioural therapy with a trained counsellor aimed at helping people to address feelings of anxiety, fear and guilt that may have an impact on sexual function;

- Pharmacological and drug treatments (e.g testosterone replacement therapy for cases of androgen insufficiency

- Phytomedical treatment

- Surgical treatment

\subsection{Behaviour therapy of erectile dysfunction}

When there is no obvious medical etiology for ED, psychosocial factors should be explored. The potential clue that psychosocial factors may be a cause is that a man is able to achieve normal erections and orgasm through masturbation or sexual stimulation with a partner other than the "index case" partner with whom he has ED (e.g., a spouse with whom there is substantial conflict). Group or individual cognitive behaviour therapy, psychosexual therapy, including sensate focus technique and therapy aimed at improving relationship difficulties (couple's theraphy) may help to improve sexual dysfunction in men. In some cases, education about medical and psychosocial etiologies of ED in conjunction with a physician reassurance may prove adequate to restore normal male sexual function [54]. Lifestyle interventions focused on modifiable health behaviours may be a safe strategy to improve ED.

\subsection{Pharmacotherapeutic treatment of erectile dysfunction}

Pharmacology of current and future therapies of erectile dysfunction depend on risk factors and conditions associated with it. Different kinds of administration have been proposed such as intracavernosal administration and non intracavernosal administration [55].

Clinical studies and experimental studies have showed positive and negative effects of the different methods of administration [55]. Pharmacotherapy involves locally acting vasoactive drugs such as papaverin and alprostadil [56] and firstline oral therapy for ED includes phosphodiesterase type 5 (PDE-5) inhibitors such as sildenafil, vardenafil, and tadalafil, which inhibit hydrolysis of the second messenger cyclic guanosine monophosphate (cGMP), the production of which is promoted by $\mathrm{NO}$ release within the penile smooth cells $[57,58]$. Various centrally acting drugs influence sexual behaviour. In particular, the dopaminergic substance apomorphine is a central enhancer that acts in the paraventricular nucleus of the hypothalamus as a dopamine (D2) receptor agonist, inducing and increasing penile erection responses following sexual stimulation via disinhibition [59].

PDE5 inhibitors have had a tremendous impact on the treatment of ED, but are not always effective (e.g., in patients with diabetes) [55]. Common adverse events with PDE inhibitors include headache (10-16\%), flushing (5-12\%), dyspepsia (4-12\%), nasal congestion (1-10\%), and dizziness (2-3\%) occurring during treatment [60]. The most successful approach to treat ED has been drugs aimed at mechanisms in the target organ. Despite significant progress, the different mechanisms involved in neurotransmission, impulse propagation, and intracellular transduction of neural signals in penile smooth muscles need further investigation. It should 
be remembered that most of the pharmacological options for ED treatment do not influence the progress of the underlying pathophysiology and do not cure the disease [55].

Testosterone therapy has been shown to normalize serum testosterone levels in patients with hypogonadism. Testosterone therapy was aimed at maintaining or restoring libido and erectile function; improving or maintaining virilization, muscle mass, strength, and bone density; and to alleviate other symptoms related to hypogonadism. There is some evidence that the addition of type 5 phosphodiesterase inhibitor can potentiate the effects of testosterone replacement in some hypogonadal men [8]. If this is unsuccessful, one should consider other treatments for ED. Because there are a wide range of pharmacotherapy options available, it would be desirable, in many instances, to offer patients an alternative to current pharmacotherapy.

\subsection{Effects of phytomedicinal plants on erectile dysfunction}

A wide variety of human disorders is currently being treated with the use of plant materials due to their decreased toxicity levels, cost-effectiveness as well as minimized side effects in order to avoid drug resistance caused by pharmacological agents 61- 63].

Plants and herbs are persistently being studied for the identification of novel therapeutic agents. Among the 250,000 higher plant species on earth, more than 80,000 plants have medicinal values [62]. Herbal medicine is still the mainstay of about $75-80 \%$ of the global population, mainly in developing countries, for primary health care because of better cultural acceptability, better compatibility with the human body and lesser side effects. The chemical constituents presenting the herbal medicine or plant are a part of the physiological functions of living flora and hence they are believed to have better compatibility with human body [64].

A traditional system of Indian medicine called Ayurveda deals with the sexual dysfunctions in a special category of treatment under the name "Vajikarna" or virilification. The system includes the use of aphrodisiacs for erectile dysfunction, spermatogenesis, semenogenesis, and methods of improving defective semen, causes of infertility, reproduction and sexual satisfaction [65].

About 317 phytochemicals are listed for antioxidant potential; 340 plants as aphrodisiac and antioxidants and 40 plants are listed for adaptogenic nature. Ethnobotanical plants contain antioxidant, aphrodisiac and adaptogenic properties [66].

Natural antioxidants are located in different parts of a plant such as wood, bark, stems, pods, leaves, fruit, roots, flowers, pollen, and seeds [67]. Natural products, mainly phytomedicine, or diet ingested by human, are antioxidants capable of terminating the free radical chain reactions [68].

Antioxidant properties in plants are due to the presence of cinnamic acids, coumarins, diterpenes, flavonoids, lignans, monoterpenes, phenylpropanoids, tannins and triterpenes [69]. Phytochemicals like carotenoids, tocopherols, ascorbates and phenols presentin plants are considered strong natural antioxidants and have an important role in health care system. Phenols, a major group with antioxidant properties, comprise subclasses suchphenolic acid, flavonoid, biflavonoid, anthocyanin andisoflavonoid [70]. Adaptogens found in plants modulate response to stress (physical, environmental, or emotional) and help regulate the 
interconnected endocrine, immune, and nervous systems. This re-regulation of a disordered or highly stressed system is achieved by metabolic regulators such as, catecholamines, glucocorticoids, cortisol, serotonin, nitric oxide (NO), cholecystokinin, corticotrophinreleasing factor (CRF), and sex hormones [71]. Chlorophytum borivilianum (Safed Musli) is often referred to as Viagra without the side effects [71]. Safed musli contains saponin and alkaloids which give musli its medicinal properties. Stigmasterol, a form of saponin is very similar in structure to testosterone and consequently can occupy the testosterone receptor sites-doorways to the cells acting like an aphrodisiac. Hecogenin has steroidal-like effects that help to synthesize anabolic hormones. Anabolic hormones allow men to retain nitrogen more readily, which helps form larger more bulging muscle during an erection.

Tribulus terrestris is a herb that has been used in the traditional medicine of China and India for centuries. The active compounds in Tribulus are called steroidal saponins. The protective effect of T. terrestris for Streptozotocin -induced diabetic rats may be mediated by inhibiting oxidative stress [72]. Oral administration of $100 \mathrm{mg} / \mathrm{kg}$ of test drug has proven anabolic effect as evidenced by body weight gain in the body and reproductive organs. Improvement in sexual behaviour of male rats was characterized by increased amount and intromission frequency. Penile erection index (PEI) was also considerably enhanced without any noticeable toxicity. The testosterone level and sperm count also significantly increased. The results are comparable to that of standard drug, sidenafil citrate. Findings of the present study validate the traditional use of T. terrestris for its role in enhancing sexual behaviour and potential to be used in the treatment of ED [73].

Ginseng is an essential constituent in traditional Chinese medicine for the treatment of sexual impotence. It is likely that this effect reflects the tonic, restorative and adaptogenic properties. It has been shown that ginsenosides relax rabbit corpus cavernosum and this effect is mediated by nitric oxide, released from endothelial or neural cells. These endothelial and neurogenic effects of ginsenosides in inducing relaxation of the corpus cavernosum may account for the aphrodisiac effect of Panax ginseng [74].

Eriosema kraussianum Zulu indigenous plants are effective remedies for the treatment of ED and/or impotence. Five pyranoisoflavones have been isolated from the rootstock of Eriosema kraussianum and were screened for smooth muscle relaxation of rabbit penile muscle. The most active of the compounds had an activity of $75 \%$ of that found in Viagra. In a test on ED rabbit penile smooth muscle, it showed an activity close to that of Viagra, thus living up to the plant its traditional use $[75,76]$.

Yohimbine is an alkaloid derived from the African yohimbe tree (Pausinystalia yohimbe). It blocks the presynaptic $\alpha$-2 adrenergic receptors in the brain, leading to reduction of brain and spinal cord norepinephrine levels. Inhibition of sympathetic tone enhances sexual arousal and NO release from penile nerves [77].

\subsection{Surgical treatment}

Patients who fail to respond to pharmacotherapy or those who want a permanent solution usually have surgical implantations of penile prosthesis. These prosthetics can either be inflatable or malleable, however most patients prefer the inflatable devices because they 
provide them with a sense of a natural erection. Inflatable devices are more expensive than malleable devices with satisfaction rates of $70-87 \%$ reported from patients after appropriate consultation [78].

Vacuum constriction devices apply negative pressure to the penis in order to draw venous blood into the penis which is then retained by application of a visible constricting band at the base of the penis (a method that seems preferable to older patients) [79]. This method yields a successful erection for intercourse that can be rated as $90 \%$. The satisfaction rates range between $27-94 \%$ but about $<30 \%$ of the patients discontinue use after 2 years because of the negative side effects that include penile pain, delayed ejaculation and numbness that occur.

Penile prosthesis can go wrong because there are two major complications involved, namely mechanical failure and infection. Infection rate is therefore reduced by the use of antibiotic prophylaxis or by using implants that are impregnated with antibiotics [80].

\section{Conclusion and recommendations}

Erectile dysfunction is an increasing global the incidence. ED is also indicative of more serious cardiovascular, psychoactive disorders. Therapeutic interventions that are successful in treating ED may be effective in treating the early stages of conditions that include atherosclerosis, angina, plaque rupture and diabetic angiopathy. One common pathological denominator in both CVD and ED is oxidative stress, that is, the overproduction of ROS, in particular, $\mathrm{O}^{2-}$ and $\mathrm{H}_{2} \mathrm{O}_{2}$. Thus there is direct relationship between oxidative stress, sexual impotency and psychoactive mechanisms that alters nitrogen oxide inhibition mechanisms significantly as stated above. Therefore it is necessary to evaluate potential of natural herbs/ extracts to correct disorders and disabilities evolved in the manifestation of ED. An ideal medicinal plant extract and or natural product will achieve biochemical, physiological, pharmacological responses on erectile dysfunction. However, because of the synergic or antagonistic effects of the contents of the natural plants, herbs or their extract, it would be a worthy to investigate on their bioavailability and properties in order to maximise their use. Moreover, further investigations in the clinical setting and qualify for clinical trials in humans are warranted.

\section{Author details}

Guillaume Aboua ${ }^{1 *}$, Claudine Manirafasha ${ }^{1}$, Boitumelo R. Mosito ${ }^{1}$, Michelle van der Linde ${ }^{2}$ and Stefan S. du Plessis ${ }^{2}$

*Address all correspondence to: abouay@cput.ac.za

1 Department of Biomedical Sciences, Faculty of Health and Wellness, Cape Peninsula University of Technology, Bellville, South Africa

2 Division of Medical Physiology, Faculty of Medicine and Health Sciences, Stellenbosch University, Tygerberg, South Africa 


\section{References}

[1] Monga M, and Geriatr. The aging penis: Erectile dysfunction. Geriatric Nephrology and Urology 1999; 9(1) 27-37

[2] Bosch RJ, Bernard F, Aboseif SR, Steif CG, Lue TF, Tanagho EA. Penile detumescence: characterization of three phases. Journal of urology 1991;146(3) 867-71

[3] Agarwal A, Kalyana CN, Rakesh KS, Craig DZ, Rupesh R. Role of Oxidative Stress in the Review Pathophysiological Mechanism of Erectile Dysfunction. American Society of Andrology 2006;27(1) 401-402

[4] Gazzaruso C, Giordanetti S, De Amici E. Relationship between erectile dysfunction and silent myocardial ischemia in apparently uncomplicated type 2 diabetic patients. Circulation 2004;110:22-26

[5] Bivalacqua TJ, Armstrong JS, Biggerstaff J, Abdel-Mageed AB, Kadowitz PJ, Hellstrom WJ, Champion HC. Gene transfer of extracellular SOD to the penis reduces O2 and improves erectile function in aged rats. American Journal of Physiology Heart Circulation Physiology 2003;284:1408-1421

[6] Grimm RHJr, Grandits GA, Prineas RJ, McDonald RH, Lewis CE, Flack JM, Yunis C, Svendsen K, Liebson PR, Elmer PJ, Jeremiah S. Long-term effects on sexual function of five antihypertensive drugs and nutritional hygienic treatment in hypertensive men and women Hypertension. Hypertension 1997;29:8-14

[7] Gitlin M. Sexual dysfunction with psychotropic drugs. Experimental Opinion in Pharmacotherapy 2004;4:2259-2269

[8] Aversa A, Bruzziches R, Francomano D, Natali M, Gareri P, Spera G. Endothelial dysfunction and erectile dysfunction in the aging man. International Journal of Urology 2010;17:38-47

[9] Cellek S, Foxwell NA, Moncada S. Two phases of nitrergic neuropathy in streptozotocin-induced diabetic rats. Diabetes 2003;52:2353-2362

[10] Morales AM, and Rojas A. Advanced glycation and endothelial functions: A link towards vascular complications in diabetes. Life Sciences 2004; 76:715-730

[11] Jevtich MJ, Khawand NY, Vidic B. Clinical significance of ultrastructural findings in the corpora cavernosa of normal and impotent men. The Journal of Urology 1990;143(2) 289-293

[12] Seftel AD, Vaziri ND, Ni Z, Razmjouei K, Fogarty J, Hampel N, Polak J, Wang RZ, Ferguson K, Block C. Advanced glycation end products in human penis: elevation in diabetic tissue, site of deposition, and possible effect through iNOS or eNOS. Urology 1997;50:1016-1026 
[13] urnett AL, Nelson RJ, Calvin DC, Liu JX, Demas GE, Klein SL, Kriegsfeld LJ, Dawson VL, Dawson TM, Snyder SH. Nitric oxide-dependent penile erection in mice lacking neuronal nitric oxide synthase. Molecular Medicine, 1996;2(3) 288-296

[14] Beckman JS, and Koppenol WH. Nitric oxide, superoxide, and peroxynitrite: the good, the bad, and ugly. American Journal of Physiology 1996;27: 1424-1437

[15] Zou H, William J, Xuesong L, Alexis L, Xiaodong W. Apaf-1, a Human Protein Homologous to C. elegans CED-4, Participates in Cytochrome c-Dependent Activation of Caspase-3. Cell press 1997;90:405-413

[16] Alderton W, Cooper C, Knowles R. Nitric oxide synthases: structure, function and inhibition. Biochemistry Journal 2001;357:593-615

[17] Kim JA, Montagnani, M, Koh KK, Quon MJ. Reciprocal relationships between insulin resistance and endothelial dysfunction: molecular and pathophysiological mechanisms. Circulation 2006;113:1888-904

[18] Dobrian D, Davies M, Schriver S. Oxidative Stress in a Rat Model of Obesity-Induced Hypertension. Hypertension 2001;37:554-560

[19] Azadzoi KM, Schulman RN, Aviram M, Siroky MB. Oxidative stress in arteriogenic erectile dysfunction. Prophylactic role of antioxidants. Journal of Urology 2005;174(1) 386-93

[20] Blanker MH, Bohnen AM, Groeneveld FP. Correlates for erectile and ejaculatory dysfunction in older Dutch men: a community based study. Journal of American Society 2001;49:436-442

[21] Esposito K, and Giugliano D. Obesity, the metabolic syndrome, and sexual dysfunction. International Journal of Impotence Research 2005;17:391-398

[22] Montorsi P, Ravagnani PM, Galli S. Association between erectile dysfunction and coronary artery disease: matching the right target with the right test in the right patient. European Urology 2006;50:721-731

[23] Corona G, Monami M, Boddi V. Male sexuality and cardiovascular risk. A cohort study in patients with erectile dysfunction. Journal of Sexual Medicine 2010;8:234-244

[24] Corona G, Forti G, Maggi M. Why can patients with erectile dysfunction be considered lucky? The association with testosterone deficiency and metabolic syndrome. Aging Male 2008;11:193-199.

[25] Virag R, Bouilly P, Frydman D. Is impotence an arterial disorder. A study of arterial risk factors in 440 impotent men. Lancet 1985;1:181-184

[26] O'Kane PD, Jackson G. Erectile dysfunction: is there silent obstructive coronary artery disease? International Journal of Clinical Practice 2001; 55:219-220 
[27] Blumentals WA. Should erectile dysfunction be considered as a marker for acute myocardial infarction? International Journal of Impotence Research 2004;16:350-353.

[28] Kaiser DR. Impaired brachial artery endotheliumdependent and independent vasodilation in man with erectile dysfunction and no other clinical cardiovascular disease. Journal of American Cardiology 2004;43:179-184

[29] Cheitlin MD. Erectile dysfunction. The earliest sign of generalized vascular disease? Journal of American Cardiology 2004;43:185-186

[30] Mannino DM, Klevens RM, Flanders WD. Cigarette smoking: an independent risk factor for impotence? American Journal of Epidemiology 1994;140

[31] Tengs TO and Osgood ND. The link between smoking and impotence: two decades of evidence. Prevalence Medicine 2001;32:447-52

[32] Hakim LS, Goldstein I. Diabetic sexual dysfunction. Endocrinology Metabolism Clinic North America 1996;25:379-400

[33] Podlasek CA, Zelner DJ, Bervig TR, Gonzalez CM, McKenna KE, McVary KT. Characterization and localization of nitric oxide synthase isoforms in the BB/WOR diabetic rat. Journal of Urology 2001;166:746-755

[34] Cersosimo E, DeFronzo RA. Insulin resistance and endothelial dysfunction: the road map to cardiovascular diseases. Diabetes Metabolic Research Review 2006;22:423-36

[35] Akishita M, Hashimoto M, Ohike Y. Low testosterone level is an independent determinant of EDys in men. Hypertension Res 2007;30:1029-34

[36] Bivalacqua TJ, Usta MF, Champion HC, Adams D, Namara DB, Abdel-Mageed AB, Kadowitz PJ, Hellstrom WJ. Gene transfer of endothelial nitric oxide synthase partially restores nitric oxide eNOS function/dysfunction in the penis synthesis and erectile function in streptozotocin diabetic rats. Journal of Urology 2003;169:1911-1917

[37] Bivalacqua TJ, Usta MF, Champion HC, Leungwattanakij S, Dabisch PA., McNamara DB, Kadowitz PJ, Hellstrom WJ. Effect of combination endothelial nitric oxide synthase gene therapy and sildenafil on erectile function in diabetic rats. International Journal of Impotence Research, 2004;16:21- 29

[38] Feldman KW. and Smith DW. Fetal phallic growth and penile standards for newborn male infants. The Journal of Pediatrics 1975;86:395-398

[39] Ehrhardt AA. and Meyer-Bhalung WSL. Prenatal Sex Hormones and the Developing Brain: Effects on Psychosexual Differentiation and Cognitive Function. Annual Review Medicine 1979;30:417-430

[40] Gooren LGJ. Archives on Sexual Behaviour 1985;14:539-548

[41] Michael RP, Rees HD, Gonsall RW. Sites in the male primate brain at which testosterone acts as an androgen. Brain Research 1989;502:11-20 
[42] Chen KK, Chan JYH, Chang LS, Chen MT, and Chan SHH. Elicitation of penile erection following activation of the hippocampal formation in the rat. Neuroscience letters 1992;141:218-222

[43] Perachio AA, Marr LD, Alexander M. Sexual behavior in male rhesus monkeys elicited by electrical stimulation of preoptic and hypothalamic areas.Brain Research 1979;177:127-144

[44] Giuliano F. and Rampin O. Neuroscience Biobehaviour Review 2000;24:517-533

[45] Costarella CE, Stallone JN, Rutecki GW, Whittier FC. Testosterone causes direct relaxation of rat thoracic aorta. Journal of Pharmaceutical Experimental Therapy 1996;277:349-54

[46] Perusquia M, Hernandez R, Morales MA, Campos MG, Villalon MG. Role of endothelium in the vasodilating effect of progestins and androgens on the rat thoracic aorta. General Pharmacology 1996;27:181-5

[47] English KM, Jones RD, Jones TH, Morice AH, Channer KS. Testosterone acts as a coronary vasodilator by calcium antagonist action. Journal of Endocrinology Investigation 2002;25:455-8

[48] Tep-areenan P, Kendall DA, Randall MD. Testosterone-induced vasorelaxation in the rat mesenteric arterial bed is mediated predominantly via potassium channels. British Journal of Pharmacology 2002;135:735-40

[49] Yildiz O, Seyrek M, Irkilata HC, Yildirim I, Tahmaz L, Dayanc M. Testosterone might cause relaxation of human corpus cavernosum by potassium channel opening action 2009

[50] Isidori AM, Giannetta E, Gianfrilli D. Effects of testosterone on sexual function in men: results of a meta-analysis. Clinical Endocrinology 2005;63:381-94

[51] AACE Hypogonadism Task Force. American Association of Clinical Endocrinologists medical guidelines for clinical practice for the evaluation and treatment of hypogonadism in adult male patients - 2002 update. Endocrinology Practice 2002;8:439456

[52] Albrecht-Betancourt A, Hijazi RA, Cunningham GR. Androgen replacement in men with hypogonadism and erectile dysfunction. Endocrine 2004;23:143-148

[53] Musicki B. and Burnettl A. eNOS. Function and Dysfunction in the Penis, Experimental Biological Medicine 2006;231:154- 165

[54] Heidelbaugh JJ. Management of Erectile Dysfunction. American Family Physician 2010;305-312

[55] Andersson KE. Mechanisms of Penile Erection and Basis for pharmacological Treatment of Erectile Dysfunction. Pharmacological reviews 2011;63:811-859 
[56] Burnett AL. Vasoactive pharmacotherapy to cure erectile dysfunction:fact or fiction? Urology 2005;65:224-230

[57] Broderick GA. Oral pharmacotherapy and the contemporary evaluation and management of erectile dysfunction. Review Urology 2003;5(7) 9-20.

[58] Omote M. Pharmacological profiles of sildenafil (VIAGRA) in the treatment of erectile dysfunction: efficacy and drug interaction with nitrate 1999;114:213-218

[59] Padma-Nathan H, Christ G, Adaikan G, Becher E, Brock G, Carrier S, Carson C, Corbin J, Francis S, DeBusk R, Eardley I, Hedlund H, Hutter A, Jackson G. phosphodiesterase inhibitor therapy for erectile dysunction,Pharmacotherapy for Erectile Dysfunction.Journal of sexual Medicine, 2004(2)128-140

[60] Hatzimouratidis K, Amar E, Eardley I, Giuliano F, Hatzichristou D, Montorsi F, Kamtchouing P, Mbongue GYF, Dimo T. Effects of aframomum melegueta and Piper guineense on sexual behaviour of male rats. Behaviour Pharmacology 2002;13:243-250

[61] Pari L, Umamaheswari J. Antihyperglycaemic activity of Musa sapientum flowers: effect on lipid peroxidation in alloxan diabetic rats. Phytotherapy Research 2000;14:1-3

[62] Ravi A, Mallika A, Venkatesh S, Arunasree MK, Vamshi KI, Madhava RB. Anticancer activity of pupalia lappacea on chronic myeloid leukemia K562 cells. DARU Journal of Pharmaceutical Sciences 2012;20:86-90

[63] Malik,J. plants for erectile dysfunction. International Journal of Natural Product Science 2011;1:9-14

[64] Sen S, Chakarborty R, Sridhar C, Reddy SR, Biplab De. Free radicals, Antioxidants, diseases and phytomedicines: current status and future prospect 2010;3(1) 91-94

[65] Tharakan B. and Manyam BV. Botanical therapies on sexual dysfunctions. Phytotherapy research 2005;19:457-463

[66] Mahajan RT, Gajare MS. Manifestation of erectile dysfunction with adaptogenic antioxidant aphrodisiac plants. International Journal of Pharmacological Biomedical Research 2012;3(1) 52-68

[67] Chanwitheesuk A, Teerawutgulrag A, Rakariyatham N. Screening of antioxidant activity and antioxidant compounds of some edible plants of Thailand. Food Chemistry 2005;92(3) 491-497

[68] Oluwaseun AA, Ganiyu O. Antioxidant properties of methanolic extracts of mistletoes (Viscum album) from cocoa and cashew trees in Nigeria. African journal of biotechnology 2008;7(1) 3138-3142

[69] Larkins N, and Wynn A. Veteranary.Clinical :Small Animals Practice 2004; 34(1) 291-298 
[70] Sule O, Salawu A, Sanni D, Decorti G, Jovana C,Tramer F, Passamonti S, Mulinacci N. Cellular antioxidant activities and cytotoxic properties of ethanolic extracts of four tropical green leafy vegetables. African Journal of Food Science 2011;5(4) 267-275

[71] Mahajan GK, Mahajan AY, Mahajan RT. Efficacy of Aphrodisiac Plants towards Improvement in Semen Quality and Motility in Infertile Males. Journal of Complementary and Integrative Medicine 2012;9:1-12

[72] Amin AMR, Lotfy M, Shafiullah M, Adeghate E. The protective effect of tribulus terrestris in diabetesAnnals of the: New York Academy of Sciences 2006;1084:391-401

[73] Singh S, Gupta Y. Aphrodisiac activity of Tribulus terrestris in experimental models in rats. Journal of Men's Health 2011;8:575-577

[74] Jain A, Bishnoi S, Mandhan V, Sodha R, Jain S. A review on aphrodisiac activities of natural plant extracts. Recent Advances in Prospects and Potential of Medicinal Plant Proceeding 2009;12:162-165

[75] Yakubu MT, Akanji MA, Oladiji AT. Male sexual dysunfuction and methods used in assessing medicinal plants with aphrodiasic potentials. Pharmacogy Review 2007;1:49-56

[76] Siegfried ED, Marion MH, Orde QM, Jabu TBD, Marion MJJ, Christopher RN natural sexual stimulant. Phytochemistry 2002; 59(3) 739-747

[77] Simonsen U, Prieto D, Hernández M, Prejunctional 2-adrenoceptors inhibit nitrergic neurotransmission in horse penile resistance arteries. Journal urology 1997;157:23-56

[78] Montague DK, Angermeier KW. Penile prosthesis implantation. Urology Clinic North America 2001;28:355-61

[79] Levine LA, Dimitriou RJ. Vacuum constriction and external erection devices in erectile dysfunction. Urology Clinic North America 2001;28:335-41

[80] Montorsi F, Rigatti P, Carmignani G. AMS three-piece inflatable implants for erectile dysfunction: a long-term multi-institutional study in 200 consecutive patients. European Urology 2000;37:50-5 
